\title{
High caries prevalence and risk factors among young preschool children in an urban community with water fluoridation
}

\section{CATHERINE H. L. HONG ${ }^{1}$, ROBERT A. BAGRAMIAN ${ }^{2}$, S. M. HASHIM NAINAR ${ }^{3}$, LLOYD H. STRAFFON ${ }^{4}$, LIANG SHEN ${ }^{5}$ \& CHIN-YING S. HSU ${ }^{6}$}

\footnotetext{
${ }^{1}$ Discipline of Orthodontics and Paediatric Dentistry, Faculty of Dentistry, National University of Singapore, Singapore, ${ }^{2}$ Department of Periodontics and Oral Medicine, School of Dentistry, The University of Michigan, Ann Arbor, MI, USA, ${ }^{3}$ Division of Pediatric Dentistry, Faculty of Dentistry, The University of Toronto, Toronto, ON, Canada, ${ }^{4}$ Department of Orthodontics and Pediatric Dentistry, School of Dentistry, The University of Michigan, Ann Arbor, MI, USA, ${ }^{5}$ Department of Biostatistics, Yong Loo Lin School of Medicine, National University of Singapore, Singapore, and ${ }^{6}$ Discipline of Oral Sciences, Faculty of Dentistry, National University of Singapore, Singapore
}

International Journal of Paediatric Dentistry 2014; 24: $32-42$

Background. Singapore is unique in that it is a $100 \%$ urban community with majority of the population living in a homogeneous physical environment. She, however, has diverse ethnicities and cultures as such; there may be caries risk factors that are unique to this population.

Aim. The aims were to assess the oral health of preschool children and to identify the associated caries risk factors.

Design. An oral examination and a questionnaire were completed for each consenting child-parent pair.

Results. One hundred and ninety children (mean age: $36.3 \pm 6.9$ months) were recruited from six community medical clinics. Ninety-two children $(48.4 \%)$ were caries active. The mean $\mathrm{d}_{123} \mathrm{t}$ and $\mathrm{d}_{123} \mathrm{~s}$ scores were $2.2 \pm 3.3$ and $3.0 \pm 5.6$, respectively. Higher plaque scores were significantly $(P<0.0005)$ associated with all measures of decay (presence of decay, dt, ds). The risk factors for severity of decay (i.e., dt and ds) include child's age, breastfeeding duration, and parents' ability to withhold cariogenic snacks from their child.

Conclusions. The high caries rate suggests that current preventive methods to reduce caries in Singapore may have reached their maximum effectiveness, and other risk factors such as child's race, and dietary and breastfeeding habits need to be addressed.

\section{Introduction}

Singapore is a small country (268 sq miles) in South-East Asia with a diverse ethnic resident population of approximately 3.2 million and a nonresident population of about 800,000 at the time of the study. The Chinese ethnic group forms the majority $(77 \%)$ of the resident population, with the Malays and Indians comprising $14 \%$ and $8 \%$, respectively.

To reduce dental decay in Singapore, fluoridation of the public water supplies was introduced in 1958 at a level of $0.7 \mathrm{ppm}$ and was

Correspondence to:

Catherine H. L. Hong, Discipline of Orthodontics and Pediatric Dentistry, Faculty of Dentistry, National University of Singapore, 5 Lower Kent Ridge Road, Singapore 11907, Singapore. E-mail: denchhl@nus.edu.sg subsequently reduced to $0.6 \mathrm{ppm}$ in $1992^{1}$. Close to $100 \%$ of the population have accessibility to fluoridated water in their homes through public piped in water lines. In addition to the fluoridation of public water supplies, a dental health programme was implemented in 1949 to provide free dental treatment for all school-aged children (7-18 years). In a 10-year water fluoridation study in Singapore, Wong et al. ${ }^{2}$ found that these efforts resulted in a $34 \%$ and $40 \%$ reduction in the caries incidence of permanent teeth in children aged 7 and 8 years, respectively. However, in another study by Lo et al. ${ }^{3}$, who examined the dental caries trends (19701994) of 6- to 18-year-old Singaporean children, the authors found that dental caries, although reduced over the years $(72 \%$ decreased to $42 \%$ ), was still common in the 
6- to 11-year-old age group, with the bulk of treatment needs existing in the primary dentition. In a recent population-based prospective study, the prevalence of dental caries among 3- to 6-year-old children (mean age: 4.8 years) was $40 \%$ and $43 \%$ of them developed dental decay annually ${ }^{4}$. This problem is not unique to Singapore; the National Health and Nutrition Examination Survey (NHANES) compared the caries trend between 1988 to 1994 and 1999 to 2002 in North America and found that although there was a significant decline in dental caries in the permanent dentition, there had been no change in the prevalence of dental caries in primary teeth among children between 2 and 11 years of age $^{5}$. Increasing prevalence of dental disease among younger children after the initial success of public health efforts to reduce dental decay is not isolated to North America and has been reported in other developed countries $^{6,7}$.

Early childhood caries (ECC) is a devastating disease with many undesirable sequelae. This virulent disease progresses rapidly and can cause significant discomfort and pain in children. Of the seven types of pain investigated by the Nuprin pain survey in the US population, dental pain was found to be most likely to disrupt sleep and daily activities ${ }^{8}$. Not only does ECC affect the teeth, the consequences of this disease may lead to other issues 9 . In the 1989 US National Health Interview Survey, it was estimated that 51 million school hours were lost annually due to dental-related issues $^{10}$. Malnutrition ${ }^{11}$, growth $\operatorname{lag}^{12}$, and poor school performance ${ }^{13}$ have also been associated with this disease progress.

As dental caries is a complex and dynamic chronic disease that develops over a relatively long period of time, carious lesions detected in a 6-year-old child would have initiated during infancy and early preschool years ${ }^{14}$. Oral health services in Singapore's current public healthcare system are primarily targeted towards school children between the ages of 7 and 18 years. Current statistics, however, suggests the need to revisit the current oral healthcare delivery services with a focus on preschool children.
Some of the well-documented factors implicated in the development of ECC include dietary habits (e.g., frequent between-meal snacks, on-demand or continuous feeding throughout the night), poor oral hygiene practices, fluoride exposure, oral microbial flora, defects in the enamel structure, presence of dental disease in parents and caregivers, demographics, and social factors ${ }^{9}$. The impact of these factors on the development of dental caries in very young Singaporean children, however, remains uncertain. Singapore is unique in that it is one of the smallest countries in the world, with virtually $100 \%$ urbanization, and thus, majority of the population live in a relatively homogeneous physical environment. However, for the size of the country, it has diverse ethnicities, languages, cultures, and religions, as such; there may be ECC risk factors that are unique to the Singaporean population. The purpose of this exploratory study was to evaluate the caries prevalence among preschool children attending public medical clinics in Singapore and to identify associated risk factors in children with high dental caries activity.

\section{Materials and methods}

\section{Sampling}

The study was conducted in 6 of 17 public health medical clinics (Bedok, Hougang, Jurong, Tampines, Woodlands, and Yishun) in Singapore. The selected clinics were situated in various parts of the island and were likely to serve areas that comprised family units with younger children. Children who visited the public health dental clinics were deliberately excluded from this study because many patients sought care at these dental clinics only when they had a dental problem.

All patients who presented at the medical clinics for routine healthy child or immunization visits were invited to participate in the study. Study participants who had active dental decay were referred by the examining dentist to the School Dental Centre (a centralized government dental clinic that provides subsidized dental care to children) for treatment. 
The study was approved by the Health Sciences Institutional Research Board (IRB) at the University of Michigan, Ann Arbor, the Centralized IRB, and the Research Ethics Committee for Singhealth and National Health Group of Singapore, respectively. The risks and benefits of the study were explained to the parents of participating children, and their consent was obtained.

\section{Oral examination}

An intraoral examination was carried out by a single operator (C.H.L.) using the knee-toknee approach. Prior to the clinical examination, the operator was calibrated for the measurement of caries and plaque scores to ensure intra-examiner reliability. This was done by having the examiner go through a series of photographs of carious lesions of incipient (D1), enamel (D2), and dentinal (D3) caries. These photographs had previously been assigned the type of carious lesion by a gold-standard examiner. Visual assessment of the dentition and the amount of plaque accumulation were determined using a disposable dental mouth mirror and an artificial light. A disposable explorer was used only when there was a strong suspicion of a carious lesion. The clinical oral examination assessed oral health status using the decayed, missing, filled teeth, and surface (dmft and dmfs) indexes. The Dl -D3 caries diagnostic criterion that accounted for initial carious lesions was used for reporting dental caries. Briefly, the D1-D3 scale categorizes the caries process into 3 stages: demineralized lesions with no loss of enamel structure (D1), lesions with loss of structure of the enamel layer (D2), and lesions with loss of both enamel and dentinal structures (D3). The amount of plaque present on the teeth was recorded using the Silness and Loe index ${ }^{15}$. The index was modified such that only the plaque on the labial surfaces of the teeth was charted ${ }^{16}$. The average plaque score was calculated from the summation of the individual plaque scores for all the teeth; the resultant value was then divided by the number of teeth present in each patient. Missing teeth were excluded from the calculation. Eleven children were randomly re-examined on the same day of the original dental examination to verify intra-operator reproducibility, and $96 \%$ intra-operator reproducibility $($ kappa $=0.908$, standard error: 0.028) was achieved for caries examination using the D1 -D3 caries diagnostic criteria.

Because of the young age of the study sample, some children did not have a full complement of their primary dentition. A tooth was considered to be unerupted if any part of the tooth was still covered by operculum. No intraoral radiographs were taken.

\section{Questionnaire}

A 23-item questionnaire was administered to elicit information regarding familial and socio-demographic factors, child's feeding practices, dietary habits, snacking frequency, oral hygiene practices, and parental views on the importance of oral health and dental care in their children. Some questions were designed to elicit yes/no answer, whereas others elicited answers based on a 5-point Likert scale. With the exception of some questions that were modified to adapt to the aims of this study, the same questionnaire had been previously tested in pilot studies at the Faculty of Dentistry, National University of Singapore. To determine the ease in completion of the questionnaire, pretesting of the questionnaire was conducted on eight patients in one of the public health clinics. Critiques were noted and revisions were made to the questionnaire.

\section{Statistical analysis}

All statistical analyses were performed using IBM SPSS version 20.0 (New York, USA). The participants' demographic and clinical data were analysed descriptively. Poisson regression with robust estimator was utilized to identify the predictors of the presence of dental caries, whereas generalized linear model for negative binomial distribution with log link was used to evaluate the predictors of ds and dt. All the potential risk factors/ indicators were initially evaluated separately, and the predictors with $P$-values $<0.1$ were subsequently included in a regression model 
with backward model selection to determine the final model.

\section{Results}

\section{Demographics}

A total of 201 children were recruited. Eleven children were excluded because of noncompliant behaviour or incomplete information in the questionnaire. Data presented were therefore based on 190 children with a mean age of $36.3 \pm 6.9$ months (range: 18-48 months). There were similar number of males $(n=98)$ and females $(n=92)$. Majority of the children were of either Chinese $(60 \%)$ or Malay $(32 \%)$ ethnicity. Due to the small number of Indian children $(7 \%)$, they were grouped under the 'Other' category for the purpose of statistical analysis. Majority of the children $(67 \%)$ were living in type 2 (4-5 rooms) government-subsidized housing, $16 \%$ in type 1 ( $1-3$ rooms) government-subsidized housing, and the remaining $(17 \%)$ in privatized (minimal or no government subsidy) housing (types 3 and 4).

\section{Dental caries and plaque}

Ninety-two $(48 \%)$ children had $\mathrm{d}_{1}, \mathrm{~d}_{2}$, or $\mathrm{d}_{3}$ carious lesions. Eighty children $(42 \%)$ had incipient carious lesions $\left(\mathrm{d}_{1}\right.$ lesions), and 58 $(31 \%)$ had enamel $\left(\mathrm{d}_{2}\right.$ lesions) and dentinal caries $\left(\mathrm{d}_{3}\right.$ lesions). The mean $\mathrm{d}_{23} \mathrm{t}$ and $\mathrm{d}_{23} \mathrm{~s}$ scores (cavitated carious lesions) were $1.0 \pm 2.2$ (range: $0-13$ teeth) and $1.5 \pm 4.2$ (range: 0-33 surfaces), respectively. When the incipient lesions were included, the mean $\mathrm{d}_{123} \mathrm{t}$ and $\mathrm{d}_{123} \mathrm{~s}$ scores increased to $2.2 \pm 3.3$ (range: 0-20 teeth) and $3.0 \pm 5.6$ (range: $0-41$ surfaces), respectively. There was no contributing ' $\mathrm{f}$ ' or ' $\mathrm{m}$ ' component because none of the children had any filled or extracted teeth. Nineteen children displayed ECC (10\%), and 73 children $(38.4 \%)$ had severe ECC.

Majority of the children (89\%) with carious lesions had maxillary incisor caries. Analysis utilizing the chi-square McNemar test revealed that there was significantly more dental caries in the maxillary incisors compared with the rest of the dentition
$(P=0.009)$. The odds ratio for a child with maxillary incisor caries to have carious lesions in the rest of the dentition was 12.7 (95\% CI: $5.79,27.69)$, with a sensitivity of $82.5 \%$ and specificity of $72.9 \%$.

The mean average plaque index was $1.3 \pm 0.8$. The average plaque score was significantly associated with the presence of dental decay $(P<0.0005)$, dt $(P<0.0005)$, and ds $(P<0.0005)$.

\section{Questionnaire}

Dietary habits. Information on child-feeding practices revealed that $23.8 \%(n=45)$ of the children were never breastfed. Of those who were breastfed, the mean age of weaning from breastfeeding was $4.8 \pm 6.9$ months (range: 0-36 months). Majority of parents $(90 \%)$ reported that their child was still using the bottle regularly for milk consumption after the age of 1 year. At the time of the study, 33 children (17\%) still fell asleep while breastfeeding or with a bottle containing milk, formula, or juice. Significantly higher number of Malay parents reported that their child was breastfed for a longer period of time $(P=0.002)$ and fell asleep while breastfeeding or with a bottle containing cariogenic substrate $(P=0.006)$ as compared to other ethnic groups.

Approximately, one in four children $(27 \%)$ consumed 2 to 3 between-meal snacks per day, whereas $4 \%(n=8)$ snacked $\geq 4$ times a day.

Tooth-brushing and fluoride use. Majority of the children $(90 \%)$ had their teeth brushed at least once a day. Of these, $38 \%$ brushed their teeth without supervision, whereas the remaining children had their teeth brushed by their parents, grandparents, or maids. Six children $(3 \%)$ were using fluoride supplements regularly.

Parental attitudes, knowledge, and practices. Most parents $(n=158,83 \%)$ agreed that baby teeth were important for their child's overall health and well-being. One hundred and thirty-four $(71 \%)$ parents strongly agreed or agreed that they made the effort to ensure 
that their child's teeth were brushed even when they were very busy. However, only $50 \%$ of the parents strongly agreed or agreed that they could withhold snacks when their child fussed for a snack.

Most parents $(82 \%)$ were knowledgeable about ECC. The top two sources of information were from books/health magazines $(14 \%)$ and health education (12\%). Only 5\% $(n=9)$ received information about ECC from their dentist or doctor. More than half of the parents $(n=123,65 \%)$ were aware of the detrimental effects of allowing their child to sleep with a bottle throughout the night.

Only $3 \%$ of the children in this study had visited the dentist. The average age that parents $(n=153)$ felt appropriate for their child to visit the dentist was $5.2 \pm 1.6$ years. Twenty-seven (14\%) parents did not know the appropriate age for their child's first dental visit. Only two (1\%) felt that their child should have his/her first dental visit at 1 year of age. The reasons given by parents for not bringing their child to the dentist are listed in Table 1.

\section{Caries risk factors}

Presence of dental caries by clinical examination (yes/ no). Using the backward Poisson regression with robust estimator, the presence of dental caries was significantly associated with the

Table 1. Reasons reported by parents for not taking their child to the dentist.

\begin{tabular}{lcc}
\hline Reasons & Frequency & Percentage (\%) \\
\hline $\begin{array}{l}\text { His/her teeth does not bother } \\
\text { him/her }\end{array}$ & 70 & 36.9 \\
Too young & 52 & 27.4 \\
Dental phobia & 18 & 9.5 \\
No need to see the dentist & 12 & 6.3 \\
Never thought about it & 9 & 4.7 \\
No time & 3 & 1.6 \\
Cannot find a suitable dentist & 1 & 0.5 \\
No idea where to go & 1 & 0.5 \\
Laziness on parent's part & 1 & 0.5 \\
No dentist is willing to & 1 & 0.5 \\
see the child & & 0.5 \\
No feedback from & 1 & \\
childcare centre & & 0.5 \\
Not sure what the & 1 & 10.6 \\
recommended age is & & \\
Not stated & 20 & \\
Total & 190 & \\
\hline
\end{tabular}

child's race $(P=0.044)$, consumption of sweet snacks $\geq 4$ times a day $(P=0.011, \mathrm{RR}=1.91$ 95\% CI 1.16-3.15), parental valuation of the importance of baby teeth $(P=0.007$, $\mathrm{RR}=1.51,95 \%$ CI 1.12-2.04), parents' ability to withhold cariogenic snacks from their child even when their child fussed $(P=0.042$, $\mathrm{RR}=1.65,95 \%$ CI 1.02-2.66), and the average plaque accumulation $(P<0.0005, \mathrm{RR}=1.52$, 95\% CI 1.30-1.77) (Table 2). Compared with the Chinese children, Malay children were more likely to have caries $(P=0.019$, $\mathrm{OR}=1.40,95 \%$ CI 1.06-1.86).

Number of decayed teeth by clinical examination $\left(d_{123} t\right)$. Using the backward generalized linear regression for negative binomial distribution, it was found that the child's age in months $(P=0.049$, mean ratio per 1 month increase $=1.03,95 \%$ CI 1.00-1.06), duration of breastfeeding for more than 10 months $(P=0.016$, mean ratio $=1.85,95 \%$ CI $1.12-$ 3.05), parents' ability to withhold cariogenic snacks from their child even when their child fussed $(P=0.018$, mean ratio $=1.92,95 \%$ CI $1.12-3.29)$, and average plaque accumulation $(P<0.0005$, mean ratio per 1 unit increase $=$ 2.32, 95\% CI 1.82-2.96) were significantly associated with $\mathrm{d}_{123} \mathrm{t}$.

Number of decay surfaces by clinical examination $\left(d_{123} s\right)$. Backward generalized linear model for negative binomial distribution found that the child's age (in months) $(P=0.012$, mean ratio per 1 month increase $=1.03,95 \%$ CI $1.00-1.06)$, type of housing $(P=0.004$, mean ratio $=2.17,95 \%$ CI $1.28-3.70)$, duration of breastfeeding for more than 10 months $(P=0.001$, mean ratio $=2.32,95 \%$ CI $1.44-$ $3.75)$, parents' ability to withhold cariogenic snacks from their child even when their child fussed $(P=0.004$, mean ratio $=2.14,95 \%$ CI 1.27-3.59), and average plaque accumulation $(P<0.0005$, mean ratio per 1 unit increase $=2.32, \quad 95 \%$ CI $1.86-2.92) \quad$ were significantly associated with $\mathrm{d}_{123} \mathrm{~S}$.

\section{Discussion}

Despite Singapore being one of the wealthier countries in terms of GDP per capita with 
Table 2. Potential risk factors for the presence of dental decay.

\begin{tabular}{|c|c|c|c|c|}
\hline Potential risk factors for the presence of dental decay $(n)$ & $P$-value & Relative risk & $\begin{array}{l}\text { Adjusted } \\
P \text {-value }\end{array}$ & Adjusted relative risk \\
\hline Child race & 0.029 & & 0.044 & \\
\hline Chinese $(n=113)$ & & 1 & & 1 \\
\hline Malay $(n=61)$ & & $1.47(1.08-1.96)$ & & $1.40(1.06-1.86)$ \\
\hline Indian/Others $(n=16)$ & & $0.88(0.45-1.72)$ & & $0.88(0.47-1.68)$ \\
\hline Breastfeed & 0.021 & & NS & \\
\hline No breastfed and breastfed till 10 months $(n=163)$ & & 1 & & \\
\hline Breastfed $>10$ months $(n=26)$ & & $1.55(1.14-2.10)$ & & \\
\hline Frequency of sweets & 0.031 & & 0.011 & \\
\hline $0-3$ times a day $(n=182)$ & & 1 & & 1 \\
\hline$\geq 4$ times a day $(n=8)$ & & $1.87(1.38-2.54)$ & & $1.91(1.16-3.15)$ \\
\hline Importance of baby teeth & 0.033 & & 0.007 & \\
\hline Very Important/Important $(n=148)$ & & 1 & & 1 \\
\hline Neutral/not important $(n=32)$ & & $1.46(1.08-1.98)$ & & $1.51(1.12-2.04)$ \\
\hline Does your child have dental decay?* & $<0.0005$ & & - & - \\
\hline None $(n=148)$ & & - & & \\
\hline Yes $(n=20)$ & & $2.47(2.03-3.00)$ & & \\
\hline Don't know $(n=21)$ & & $1.41(0.93-2.14)$ & & \\
\hline $\begin{array}{l}\text { Parents' attitude: ability to withhold frequent sugar } \\
\text { snacks from my child between meals even when } \\
\text { they are crying for it: }\end{array}$ & 0.014 & & 0.042 & \\
\hline Strongly agree $(n=34)$ & & 1 & & 1 \\
\hline Agree/Neutral/disagree/strongly disagree $(n=156)$ & & $1.79(1.04-3.07)$ & & $1.65(1.02-2.66)$ \\
\hline Average plaque accumulation & $<0.0005$ & $1.61(1.39-1.86)$ & $<0.0005$ & $1.52(1.30-1.77)$ \\
\hline
\end{tabular}

*The variable was not included in the regression.

virtually $100 \%$ urbanization and fluoridation of all water supplies, close to half of 18- to 48-month-old children in this study had dental caries. Utilizing the National Institute of Dental and Cranial Research case definition of ECC, majority of the children with dental caries had severe ECC ${ }^{17}$. As part of an international collaborative effort in 2002, Pine et ll. $^{18}$ evaluated the prevalence of dental caries in Singaporean children and found that dental caries was a serious problem in this country. The dmft (3.8) observed in Pine et al.'s (2004) study ${ }^{18}$ was higher than that in our study (2.2), and this could be due to the older children sampled in her study, contributing ' $\mathrm{f}$ ' component, and the high-risk participants recruited from the School Dental Center (SDC) and kindergartens. Despite differences between the studies, both clearly indicate the high levels of dental disease in young Singaporean children. This compares unfavourably with figures from Hong Kong: a jurisdiction with comparable GDP per capita to Singapore, where the percentage of children with cavitated lesions $(17 \%, 2.8$ years \pm
0.6 months) is almost half that of Singaporean children $(31 \%)$ of approximately similar ages $^{19}$. These caries statistics suggest that current preventive methods in Singapore (e.g., water fluoridation, subsidized dental treatment for school-age children) may have reached their maximum effectiveness in the reduction in dental caries.

Majority of caries-active children had maxillary incisor caries, and the presence of dental caries in the maxillary incisors carried a high odds ratio for the child to have caries in the rest of the dentition. This caries pattern is not unique to this study and has been demonstrated in other studies ${ }^{20,21}$. Alaluusua et al. ${ }^{16}$ reported that visible plaque on the labial surfaces of maxillary incisors could predict the caries status of very young children (sensitivity: 83\%; specificity: 92\%). The results of this study confirmed that an assessment of the presence of caries and the plaque accumulation of the 4 maxillary incisors may serve as an alternative to a full oral examination especially during public health epidemiology studies and be utilized by physicians 
Table 3. Potential risk factors for decayed and filled teeth (dt).

\begin{tabular}{|c|c|c|c|c|}
\hline Potential risk factors for $\mathrm{dt}(n)$ & $P$-value & Mean ratio & Adjusted $P$-value & Adjusted ration of mean \\
\hline Child race & 0.004 & & NS & \\
\hline Chinese $(n=113)$ & & 1 & & \\
\hline Malay $(n=61)$ & & $1.75(1.21-2.54)$ & & \\
\hline Indian/Others $(n=16)$ & & $1.95(1.06-3.58$ & & \\
\hline Child's age in months & 0.029 & $1.03(1.00-1.05)$ & 0.049 & $1.03(1.00-1.06)$ \\
\hline Breastfeed category 2 (brfedcat2) & $<0.0005$ & & 0.016 & \\
\hline No breastfed and breastfed till 10 months $(n=163)$ & & 1 & & 1 \\
\hline Breastfed $>10$ months $(n=26)$ & & $2.64(1.66-4.21)$ & & $1.85(1.12-3.05)$ \\
\hline Drinks when going to bed/during night & $<0.0005$ & & NS & \\
\hline Nothing/bottle of water/pacifier only $(n=157)$ & & 1 & & \\
\hline Nursing/milk/formula/juice/something sweet $(n=33)$ & & $2.43(1.59-3.73)$ & & \\
\hline Importance of baby teeth & 0.005 & & NS & \\
\hline Very Important / Important $(n=148)$ & & 1 & & \\
\hline Neutral/not important $(n=32)$ & & $1.87(1.21-2.90)$ & & \\
\hline Is sleeping with the bottle bad? & 0.006 & & NS & \\
\hline Yes $(n=123)$ & & 1 & & \\
\hline No/Don't know $(n=67)$ & & $1.64(1.15-2.34)$ & & \\
\hline Does your child have dental decay?* & $<0.0005$ & & - & - \\
\hline None $(n=148)$ & & 1 & & \\
\hline Yes $(n=20)$ & & $4.35(2.60-7.27)$ & & \\
\hline Don't know $(n=21)$ & & $1.80(1.05-3.10)$ & & \\
\hline $\begin{array}{l}\text { Parents' attitude: I can do a good job brushing my child's } \\
\text { teeth each day thoroughly even when I am very busy }\end{array}$ & 0.002 & & NS & \\
\hline Strongly agree $(n=42)$ & & 1 & & \\
\hline Agree/Neutral/disagree/strongly disagree $(n=148)$ & & $2.05(1.30-3.22)$ & & \\
\hline $\begin{array}{l}\text { Parents' attitude: ability to withhold frequent sugar } \\
\text { snacks from my child between meals even when } \\
\text { they are crying for it: }\end{array}$ & 0.026 & & 0.018 & \\
\hline Strongly agree $(n=34)$ & & 1 & & 1 \\
\hline Agree/Neutral/disagree/strongly disagree $(n=156)$ & & $1.73(1.07-2.80)$ & & $1.92(1.12-3.29)$ \\
\hline Average plaque accumulation & $<0.0005$ & $2.45(1.94-3.07)$ & $<0.0005$ & $2.32(1.82-2.96)$ \\
\hline
\end{tabular}

*The variable was not included in the regression model.

and mid-level healthcare providers to detect caries in young children.

At the time of the study, very few Singaporean children had been to a dentist. Furthermore, these children visited the dentist only because they had dental decay requiring attention. Thus, this practice was not protective in the caries risk assessment, but rather appeared to be a consequence of the child having dental decay.

In contrast to only $1 \%$ in Singapore, $37 \%$ of Hong Kong parents indicated that the first dental visit for their child should be around 1 year of age ${ }^{22}$. The American Academy of Pediatric Dentistry recommends that all children should have their first dental visit no later than 12 months of age ${ }^{23}$. Many Singaporean parents were unaware of the appropriate age for their child to have their first dental visit and felt that a visit to the dentist was warranted only if their child had tooth pain. Of those who reported an age, 5 years was thought by many parents to be an appropriate time for their child's first dental visit in our study. Many parents cited that their child did not require regular dental check-ups because they did not complain about their teeth. Homecare practices also appeared to be poor; close to $40 \%$ of children were brushing their teeth without supervision, a practice that is not aligned with the AAPD guidelines ${ }^{24}$. These worrisome attitudes and practices suggest that the establishment of a dental home at an early age was not a priority for Singaporean parents. Currently, the school dental health programme in Singapore provides free dental examination and treatment for school children (7 years of age and older), and this may have influenced parental perception on the appropriate age to visit the dentist. Additionally, there were no formalized public 
Table 4. Potential risk factors for decayed and filled surfaces (ds).

\begin{tabular}{|c|c|c|c|c|}
\hline Potential risk factors for ds $(n)$ & $P$-value & Mean ratio & Adjusted $P$-value & Adjusted ration of mean \\
\hline Child race & $<0.0005$ & & NS & \\
\hline Chinese $(n=113)$ & & 1 & & \\
\hline Malay $(n=61)$ & & $2.01(1.40-2.87)$ & & \\
\hline Indian/Others $(n=16)$ & & $2.14(1.19-3.84)$ & & \\
\hline Child's age in months & 0.003 & $1.03(1.01-1.06)$ & 0.012 & $1.03(1.00-1.06)$ \\
\hline Type of housing & 0.001 & & 0.004 & \\
\hline HDB $1-3$ room $/ 4-5$ room $(n=158)$ & & $2.22(1.37-3.60)$ & & $2.17(1.28-3.70)$ \\
\hline Executive apt/Private $(n=32)$ & & 1 & & 1 \\
\hline Breastfeed category 2 (brfedcat2) & $<0.0005$ & & 0.001 & \\
\hline No breastfed and breastfed till 10 months $(n=163)$ & & 1 & & 1 \\
\hline Breastfed $>10$ months $(n=26)$ & & $3.02(1.93-4.74)$ & & $2.32(1.44-3.75)$ \\
\hline Drinks when going to bed/during night & $<0.0005$ & & NS & \\
\hline Nothing/bottle of water/pacifier only $(n=157)$ & & 1 & & \\
\hline Nursing/milk/formula/juice/something sweet $(n=33)$ & & $3.13(2.07-4.71)$ & & \\
\hline Importance of baby teeth & 0.004 & & NS & \\
\hline Very Important/Important $(n=148)$ & & 1 & & \\
\hline Neutral/not important $(n=32)$ & & $1.87(1.23-2.85)$ & & \\
\hline Does your child have dental decay?* & $<0.0005$ & & - & - \\
\hline None $(n=148)$ & & 1 & & \\
\hline Yes $(n=20)$ & & $5.54(3.36-9.13)$ & & \\
\hline Don't know $(n=21)$ & & $2.05(1.22-3.44)$ & & \\
\hline $\begin{array}{l}\text { Parents' attitude: I can do a good job brushing my child's } \\
\text { teeth each day thoroughly even when I am very busy }\end{array}$ & $<0.0005$ & & NS & \\
\hline Strongly agree $(n=42)$ & & 1 & & \\
\hline Agree/Neutral/disagree/strongly disagree $(n=148)$ & & $2.35(1.52-3.62)$ & & \\
\hline $\begin{array}{l}\text { Parents' attitude: ability to withhold frequent sugar } \\
\text { snacks from my child between meals even when } \\
\text { they are crying for it }\end{array}$ & 0.011 & & 0.004 & \\
\hline Strongly agree $(n=34)$ & & 1 & & 1 \\
\hline Agree/Neutral/disagree/strongly disagree $(n=156)$ & & $1.80(1.14-2.84)$ & & $2.14(1.27-3.59)$ \\
\hline Average plaque accumulation & $<0.0005$ & $2.47(2.00-3.06)$ & $<0.0005$ & $2.32(1.86-2.92)$ \\
\hline
\end{tabular}

*The variable was not included in the regression model.

health dental services for toddlers and preschool children, which may explain the low awareness of the merits of preventive dental visits and subsequent utilization rate among preschool children.

Although the history of breastfeeding (yes/ no) did not impact caries experience, the duration of breastfeeding was significantly associated with the presence of dental decay, $\mathrm{dt}$, and $\mathrm{ds}$ in the bivariate analysis. We attempted to determine the cut-off age whereby breastfeeding was considered detrimental for dental decay by categorizing the breastfeeding duration into various time points. Of the various time points analysed, we chose to segregate children at the 10month mark and found that children who breastfed for more than 10 months were significantly more likely to have severe dental decay (dt and ds) in this study. Gao et al.'s
(2010) study also identified prolonged breastfeeding as a predictor for caries occurrence ${ }^{4}$. However, in her study, increased caries risk was associated with prolonged breastfeeding for ' $1-2$ years' and 'beyond 2 years' in comparison with those for ' $<12$ months'. Despite the difference in the duration of breastfeeding, both studies suggest that the duration, rather than the history of breastfeeding, may play a significant role in caries activity. Some of the proposed hypotheses for this phenomenon may be because older children who continue to breastfeed had an overall higher number of food intakes per day than those who were weaned off breastfeeding at an earlier age. Erickson et al. ${ }^{25}$ proposed that although breast milk alone would not cause ECC, it could potentially aggravate ECC severity when combined with other carbohydrates. The data on breastfeeding and its 
impact on early childhood caries are limited, and more studies are needed to investigate this relationship.

Malay children had significantly higher prevalence of dental decay (yes/no) but no difference in severity of dental decay when compared with children of the other ethnicities. This may be attributed to several cariogenic homecare practices in Malay children. Compared with parents of other ethnicities, Malay parents were more likely to report that their child fell asleep while breastfeeding or drinking from a bottle containing milk, juice, or something sweet $(P=0.012)$, were more likely to breastfeed their children for a longer duration $(P=0.002)$, and were also less likely to withhold between-meal cariogenic snacks from their children when they fussed for them $(P=0.047)$. Similar observations were found in Gao et al.'s (2010) study, where the Malay ethnicity had a significant link to oral homecare practices and caries rate ${ }^{4}$. The differences in homecare practices, however, were not identified in that study.

Adair et al. ${ }^{26}$ established that parental attitudes and their perceived ability to control their children's tooth-brushing and sugarsnacking habits could significantly impact the establishment of habits favourable to oral health. Gao et al.'s (2010) study demonstrated that specific knowledge, such as the awareness of the detrimental effect of bedtime feeding and the awareness of sugar as the main reason for caries, was more important than generic parental knowledge or attitude (e.g., the awareness of early childhood caries) in influencing oral homecare practices ${ }^{4}$. This phenomenon was evident in this study where dental caries was high, despite the majority $(>80 \%)$ of parents reporting that they were knowledgeable about ECC. While, specific parental behaviours such as parents' perceived ability to withhold frequent cariogenic snacks from their children even when they fussed for it was inversely associated with the presence of dental decay in their child. Not all beneficial practices, however, had beneficial effects on dental caries; in this study, the frequency of tooth-brushing and/or toothbrushing with supervision did not have a positive influence on the child's caries experience. Although this agrees with some studies $^{27,28}$, others have reported lower caries levels associated with frequent tooth-brushing $^{20,29}$. The controversial results and conclusions may be due to acidogenicity of biofilm or poor tooth-brushing techniques of children and/or their caregivers. Interestingly, none of the factors mentioned in this section were significantly associated with $\mathrm{dt} / \mathrm{ds}$, implying the role of other more important indicators when assessing caries severity. Nevertheless, the information derived from both Gao et al.'s $(2010)^{4}$ and this study provides practical guidelines to steer health promotion efforts to specifically target certain knowledge and practices, especially for children and parents with higher caries rate in Singapore.

Because of the perceived discomfort of many individuals with the disclosure of their family income, the type of dwelling was chosen to measure the socio-economic status (SES) in this study. In this study, the caries experience was not consistently associated with the type of dwelling, a relationship that has been otherwise well documented in other published reports ${ }^{4,30}$. The inconsistent association could have been a function of the sampling from the public health medical clinics, which itself may be selective for patients from the lower socio-economic group. The utilization of the type of housing may also be a crude measure for the measurement of socioeconomic status in Singapore as it does not account for the extremely high housing cost in Singapore (e.g., more than 50\% of the population live in government housing developments) as well as other social and cultural factors that may be unique in this country (e.g., extended family units etc).

The limitations of this study include intraoperator reliability, small sample size, convenience sampling, the potential underestimation of caries experience because only a visual-tactile examination, without radiographs, was employed, and the innate inaccuracies in the answers encountered in the interviewer-administered questionnaire (e.g., truthful answers). Improvements to the current questionnaire could be made in future studies by the inclusion of specific questions with regard to fluoride intake (e.g., use of 
water filter and brand, use of bottled water), and the usage of household income, albeit sensitive among participants, is likely a more accurate reflection of socio-economic status.

In conclusion, this study demonstrated that despite being an affluent country with 100\% fluoridation of water supplies, caries remains high in preschool children in Singapore. Malay children, a minority group, had more dental decay compared with other ethnic groups, which may be attributed to certain cariogenic homecare practices that were more prevalent in this group. Of interest, the study found that prolonged breastfeeding, although not associated with the presence of decay, contributed to the severity of dental decay in this population. Collectively, these findings suggest that despite past successes with current preventive methods to reduce caries, other risk factors such as child's race, and dietary and breastfeeding habits need to be addressed to lower caries levels in Singapore.

Why this paper is important to paediatric dentists

- Despite being a fully urbanized and $100 \%$ fluoridated country, the occurrence of dental caries ( $\mathrm{dt}$ and ds scores of 2.2 and 3.0, respectively) was high in 18- to 48-month-old preschool children in Singapore. This highlights the need to focus on other contributory risk factors such as dietary habits that may be unique in certain minority races and other cariogenic habits such as the extended length of breastfeeding.

\section{Conflict of interest}

The authors declare that they have no conflict of interest.

\section{References}

1 Loh T. Thirty-eight years of water fluoridation-the Singapore scenario. Community Dent Health 1996; 13 (Suppl 2): 47-50.

2 Wong MQ, Goh SW, Chan J. National dental health survey of school population 1970. Singapore : Ministry of Health, Dental Branch.

3 Lo GL, Bagramian RA. Declining prevalence of dental caries in school children in Singapore. Oral Dis 1997; 3: 121-125.

4 Gao XL, Hsu CY, Xu Y, Hwarng HB, Loh T, Koh D. Building caries risk assessment models for children. J Dent Res 2010; 89: 637-643.
5 Beltran-Aguilar ED, Barker LK, Canto MT et al. Surveillance for dental caries, dental sealants, tooth retention, edentulism, and enamel fluorosis-United States, 1988-1994 and 1999-2002. MMWR Surveill Summ 2005; 54: 1-43.

6 Armfield JM, Spencer AJ. Quarter of a century of change: caries experience in Australian children, 1977-2002. Aust Dent J 2008; 53: 151-159.

7 Haugejorden O, Birkeland JM. Evidence for reversal of the caries decline among Norwegian children. Int $J$ Paediatr Dent 2002; 12: 306-315.

8 Humphrey Taylor NMC. The Nuprin Pain Report: L. Harris and Associates; 1985.

9 Tinanoff N, Reisine S. Update on early childhood caries since the Surgeon General's Report. Acad Pediatr 2009; 9: 396-403.

10 Gift HC, Reisine ST, Larach DC. The social impact of dental problems and visits. Am J Public Health 1992; 82: 1663-1668.

11 Acs G, Lodolini G, Kaminsky S, Cisneros GJ. Effect of nursing caries on body weight in a pediatric population. Pediatr Dent 1992; 14: 302-305.

12 Ayhan H, Suskan E, Yildirim S. The effect of nursing or rampant caries on height, body weight and head circumference. J Clin Pediatr Dent 1996; 20: 209-212.

13 Blumenshine SL, Vann WF Jr, Gizlice Z, Lee JY. Children's school performance: impact of general and oral health. J Public Health Dent 2008; 68: 82-87.

14 Crall JJ. Rethinking prevention. Pediatr Dent 2006; 28: 96-101; discussion 92-8.

15 Loe $H$. The Gingival Index, the Plaque Index and the Retention Index Systems. J Periodontol. 1967; 38: Suppl:610-616.

16 Alaluusua S, Malmivirta R. Early plaque accumulation-a sign for caries risk in young children. Community Dent Oral Epidemiol 1994; 22 (5 Pt 1): 273-276.

17 Drury TF, Horowitz AM, Ismail AI, Maertens MP, Rozier RG, Selwitz RH. Diagnosing and reporting early childhood caries for research purposes. A report of a workshop sponsored by the National Institute of Dental and Craniofacial Research, the Health Resources and Services Administration, and the Health Care Financing Administration. J Public Health Dent 1999; 59: 192-197.

18 Pine CM, Adair PM, Nicoll AD et al. International comparisons of health inequalities in childhood dental caries. Community Dent Health 2004; 21 (1 Suppl): 121-130.

19 King NM, Wu II, Tsai JS. Caries prevalence and distribution, and oral health habits of zero- to fouryear-old children in Macau, China. J Dent Child (Chic) 2003; 70: 243-249.

$20 \mathrm{Chu} \mathrm{CH}$, Fung DS, Lo EC. Dental caries status of preschool children in Hong Kong. Br Dent $J$ 1999; 187: 616-620; discussion 05.

21 Alm A, Wendt LK, Koch G, Birkhed D. Oral hygiene and parent-related factors during early childhood in relation to approximal caries at 15 years of age. Caries Res 2008; 42: 28-36. 
22 Chan SC, Tsai JS, King NM. Feeding and oral hygiene habits of preschool children in Hong Kong and their caregivers' dental knowledge and attitudes. Int J Paediatr Dent 2002; 12: 322-331.

23 Policy on the Dental Home. American Academy on Pediatric Dentistry Council on Clinical Affairs. Pediatr Dent 2008-2009; 30(7 Suppl): 22-23.

24 Guideline on Infant Oral Health Care. American Academy on Pediatric Dentistry Clinical Affairs Committee-Infant Oral Health Subcommittee; American Academy on Pediatric Dentistry Council on Clinical Affairs. Pediatr Dent 2008-2009; 30(7 Suppl): 90-93.

25 Erickson PR, Mazhari E. Investigation of the role of human breast milk in caries development. Pediatr Dent 1999; 21: 86-90.

26 Adair PM, Pine CM, Burnside G et al. Familial and cultural perceptions and beliefs of oral hygiene and dietary practices among ethnically and socio- economically diverse groups. Community Dent Health 2004; 21 (1 Suppl): 102-111.

27 Qin M, Li J, Zhang S, Ma W. Risk factors for severe early childhood caries in children younger than 4 years old in Beijing, China. Pediatr Dent 2008; 30: $122-128$.

28 Southward LH, Robertson A, Edelstein BL et al. Oral health of young children in Mississippi Delta child care centers: a second look at early childhood caries risk assessment. J Public Health Dent 2008; 68: 188195.

29 Jackson RJ, Newman HN, Smart GJ et al. The effects of a supervised toothbrushing programme on the caries increment of primary school children, initially aged 5-6 years. Caries Res 2005; 39: 108-115.

30 Reisine ST, Psoter W. Socioeconomic status and selected behavioral determinants as risk factors for dental caries. J Dent Educ 2001; 65: 1009-1016. 